\title{
Editorial
}

\section{Comunicación política en la era postcovid}

\author{
Marco LÓPEZ \\ PUCE Quito (Ecuador) \\ MVLOPEZ@puce.edu.ec
}

Chasqui, revista impulsada por el Centro Internacional de Estudios Superiores de Comunicación para América Latina (CIESPAL), se ha consolidado en estos casi 50 años como una tribuna de diálogo y pensamiento, tanto para académicos, comunicólogos y estudiantes de Latinoamérica, el caribe y parte de la zona ibérica.

En este número -148- se han presentado trabajos importantes guiados en la temática: "El subsuelo de lo político: Sustratos sociales, culturales, comunicacionales y tecnológicos de la acción colectiva en América Latina en el siglo XXI", que en palabras de sus coordinadores expone a

la economía, la cultura, la comunicación, la religión, en general lo social y, sobre todo, la política (entendida como un conjunto de prácticas, formas de pensar e instituciones que regulan y organizan la convivencia humana) han experimentado una variedad de cambios, transiciones y transformaciones que se han acelerado durante las dos primeras décadas del siglo XXI. Lo político, el conflicto, el antagonismo y el desacuerdo, según los supuestos del pensamiento filosófico posfundacional, se han destacado por ser elementos aceleradores. Mejor aún, lo político es comprendido desde esta perspectiva como un momento instituyente de dichas transformaciones. Su principal característica es el ser inasible y contingente. Lo político se manifiesta como una dimensión ontológica de la política. (Villarreal \& Rescher, 2021)

Que importante reflexión plantea esta convocatoria, si miramos la realidad sociopolítica de nuestras naciones veremos todavía un fruto inmaduro que se mueve al vaivén del populismo, visto claro desde la comunicación, la cultura y los propios medios.

Recordemos que la práctica político-democrática en América Latina genera dos cambios principales. Por un lado, una liberalización de sus regímenes políticos: mayor pluralismo político, tolerancia hacia la oposición y respeto de 
las libertades públicas; $y$, por otro lado, una mayor participación popular directa o indirecta (Rey, Barragán y Hausmann, 1992).

Los criterios expuestos en esta convocatoria muestran pues, los criterios que se relacionan como principios centrales de la construcción de la política pensando en "hasta qué punto la ciudadanía coincide con valores democráticos tales como la libertad, participación, tolerancia, la búsqueda de acuerdos mutuos, etc.”; no obstante, esta definición se acerca más a la conceptualización de una política plena. La construcción social y cultural por otro lado supone una activa "participación de la ciudadanía en la vida pública, la existencia de organizaciones sociales autónomas y el fortalecimiento del tejido social. Parecería que no pudo garantizarse este piso social, dado el papel central" (Paz y Miño, 2016).

Adicionalmente, la participación plena no pudo consolidarse ya que entró en una época marcada por grandes tensiones con crisis social y económica: la aplicación de políticas de ajuste estructural intensificó las desigualdades. Posteriormente, a lo largo de la década de 1990, factores como los conflictos internos y la desigualdad con la mala distribución de la riqueza han impedido la consolidación de un modelo social.

Considerando los postulados de Gerardo Munck (2013) respecto a la calidad de la política, en Latinoamérica no solo se han analizado los procesos de democratización y transición desde las dictaduras de finales de siglo XX, sino que se ha evidenciado la necesidad de medir la calidad de la política a partir de la forma en que esta "se vive y se percibe" por parte de los ciudadanos. Es decir, el foco de atención se traslada desde la forma en que la política se instaura, hacia la forma en que llega a la población.

Los distintos procesos democráticos latinoamericanos demuestran que no existió uniformidad en estas transiciones y que la consolidación ha sido difícil y variada, en algunos casos con avances importantes y en otros con retrocesos. Esto demuestra que, pese a los avances en materia de garantías constitucionales de institucionalidad democrática, los poderes políticos han logrado sobrepasar estos límites, dejando al Estado en indefensión ante su propia incapacidad de instaurarse en tanto Estado constitucional de derecho.

Así, la calidad de la política debería pensarse considerando la multiplicidad de factores que influyen en su vivencia, que no se reducen a las estructuras estatales en un determinado modelo de gobierno, sino que abarcan las dimensiones legales, socioeconómicas, culturales y políticas en las cuales la ciudadanía interactúa diariamente.

En este contexto el trabajo realizado por los editores temáticos José Antonio Villarreal y Gilberto Rescher, en medio la una pandemia que que ha cambiado todas las dinámicas del diario vivir constituye un gran aporte para la región. 


\section{Referencias bibliográficas}

Munck, G. (2013). Conceptualizing the quality of democracy: the framing of a new agenda for comparative politics. In G. Munck, \& S. Mantilla, La calidad de la democracia: perspectivas desde América Latina (pp. 11-58).

Paz y Miño, J. (2006). Ecuador: Una democracia inestable. Historia Actual Online - HAOL, 89-99.

Rey, J. C., Barragán, J., Hausmann, R., \& Alzuru, A. (1992). América Latina, alternativas para la democracia. Caracas, Venezuela: Monte Avila Editores.

Villarreal, J., \& Rescher, G. (2021). El subsuelo de lo político: Sustratos sociales, culturales, comunicacionales y tecnológicos de la acción colectiva en América Latina en el siglo XXI. Chasqui. Revista Latinoamericana de Comunicación, 1(148). doi:https://doi.org/10.16921/ chasqui.v1i148.4650 
